\title{
A teologia em busca de legitimidade científica: um olhar sobre o cenário atual
}

\author{
Theology in search of scientific legitimacy: \\ a look at the current scenario
}

\section{La teologia en busca de legitimidad científica: una mirada sobre el escenario actual}

Denis Alves de Souza*

\begin{abstract}
RESUMO
O propósito deste artigo é apresentar um quadro sobre a atual situação da teologia enquanto curso superior no Brasil. Apesar de um recente processo de reconhecimento da Teologia como curso superior, na esfera política, ainda há desafios a serem superados no que tange ao estabelecimento de uma legitimação epistemológica. Assim, apresentaremos alguns dados que auxiliarão na compreensão do campo teológico, bem como algumas iniciativas tomadas pela comunidade teológica em busca de seu status científico-acadêmico, nos níveis de graduação e pós-graduação (stricto sensu).

Palavras-chave: teologia, formação teológica superior, teologia pública.
\end{abstract}

\begin{abstract}
The purpose of this article is to present a picture about the current situation of theology as a higher education in Brazil. Despite a recent process of recognition of theology as a higher education course in the political sphere, there are still challenges to be overcome in establishing an epistemological legitimation. Thus, we will present some data that will help in the understanding of the theological field, as well as some initiatives taken by the theological community in search of its scientific and academic status, at undergraduate and postgraduate levels (stricto sensu).

Keywords: theology, highertheologicalformation, publictheology.

\section{RESUMEN}

El propósito de este artículo es presentar un cuadro sobre la actual situación de la teología como curso superior en Brasil. A pesar de un reciente proceso de reconocimiento de la teología como curso superior, en la esfera política, todavía hay desafíos a ser superados en lo que se refiere al establecimiento de una legitimación epistemológica. Así, presentaremos algunos datos que ayudarán en la comprensión del campo teológico, así como algunas iniciativas tomadas por la comunidad teológica en busca de su status científico-académico, en los niveles de graduación y postgrado (stricto sensu).

Palabras clave: teología, formación teológica superior, teología pública.
\end{abstract}

* Mestre e doutorando em Educação pela Universidade Estadual de Campinas (UNICAMP). Membro do grupo de estudos e pesquisa em diferenciação sociocultural (GEPEDISC/UNICAMP). 


\section{O status da teologia como curso superior}

Em países com instituições educacionais mais antigas do que as nossas, o curso de Teologia possui larga tradição acadêmica, herdada do período medievo. A aceitação da teologia como parte integrante do catálogo das ciências, legitimadas, política e epistemologicamente, constata-se pela sua inclusão em importantes universidades, como Harvard, Yale, Oxford, Cambridge, Heidelberg, entre outras. Entretanto, no caso específico do Brasil, a graduação em teologia foi equiparada aos demais cursos da área de humanas apenas em 1999, mediante o Parecer CNE/CES n²41/1999, que institucionalizou o ensino teológico no país. Até então, o curso superior de teologia - na modalidade livre - restringiu-se à esfera privada. Observou Passos (2011, p. 58) que a produção e difusão do conhecimento teológico alcançavam apenas o âmbito eclesial e respondia às demandas deste. Correspondia, em geral, às práticas religiosas, formação de clérigos e não gozava de qualquer relevância pública, no tocante ao exercício acadêmico.

Com pouco mais de uma década de reconhecimento da teologia como curso superior, nota-se um vertiginoso crescimento de instituições que passaram a ofertar o curso. Além da própria expansão do ensino superior - majoritariamente privado -, no caso da teologia, é determinante o crescimento demográfico do grupo denominado evangélico, sobretudo os pentecostais (MENDONÇA, 2008, p.129-132). ${ }^{1}$

\section{Gráfico $1^{2}$}

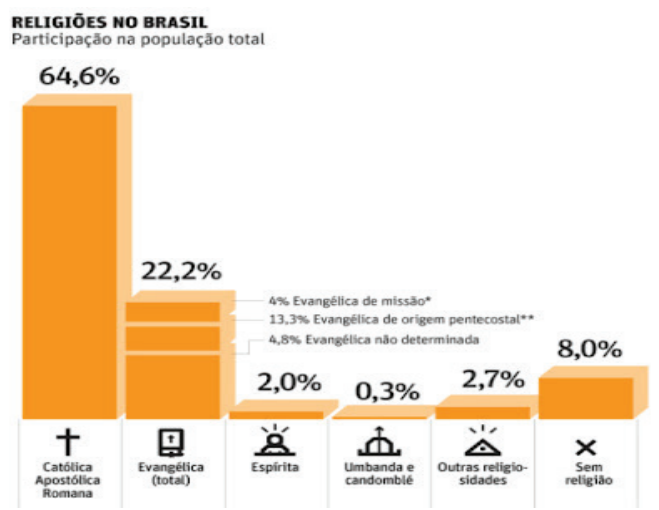

\footnotetext{
De acordo com o professor Antônio Gouveia Mendonça, o movimento também é conhecido como religião do espírito. Além das doutrinas protestantes elementares, o pentecostalismo adiciona a crença na atualidade dos dons do Espírito Santo, com ênfase na glossolalia (falar em línguas estranhas) no molde da experiência na reunião dos apóstolos na festa de pentecostes, 50 dias após a ressurreição de Cristo; também a prática de revelações individuais que podem ser dirigidas por qualquer participante, geralmente acompanhando tendências individuais como: emotividade, misticismo ou estados de exaltação. E, ainda, certa aversão ao cumprimento às normas e doutrinas da Igreja, pelo entendimento de que a iluminação do Espírito Santo revela tudo o que é necessário para a vida religiosa, inclusive a conduta. MENDONÇA, Antônio G. Protestantes, pentecostais \& ecumênicos: o campo religioso e seus personagens. $2^{a}$ ed. São Bernardo: Universidade Metodista de São Paulo, 2008.

2 https://www.conic.org.br/portal/noticias/737-os-qsem-religiaoq-do-brasil-ganham-destaque-em-jornais-da-europa.
} 
Segundo o último censo do IBGE, ${ }^{3}$ os evangélicos representam $22 \%$ da população brasileira. Se comparado ao censo anterior, houve um crescimento de 100\% em 10 anos. Tal expansão tem despertado o interesse de cientistas políticos, sociólogos, juristas, educadores, jornalistas e antropólogos, que se dedicam a analisar como este fenômeno se relaciona com suas respectivas áreas. Ao analisar as instituições de ensino mais a frente, voltaremos aos pentecostais.

O estabelecimento da teologia enquanto conhecimento institucionalizado, ainda sob análise de Passos, depende da chancela legitimadora formada pela tríade: Estado, igreja, instituições de ensino. Para tanto, são cruciais dois fatores: a) o desfecho sobre a base curricular comum; b) construção de uma comunidade científica própria, que garanta a autonomia e a emancipação da teologia enquanto subárea da filosofia. Em suma, adquirir seu espaço próprio, fazendo parte do grupo de ciências publicamente instituídas no âmbito do governo federal (PASSOS, 2011, p.59).

\section{Base Curricular Comum}

Fomentada desde 2010, a Diretriz Curricular Comum ${ }^{4}$ para o curso de teologia tem sua homologação na Resolução nº 4 /Setembro de 2016. Houve uma ampla mobilização no interesse de se estabelecer uma diretriz curricular para o curso, por parte das principais instituições teológicas do país. ${ }^{5}$ Passados cinco anos da publicação do artigo de Passos, o prognóstico feito pelo autor em relação à diretriz curricular comum, sendo uma condicional para o reconhecimento do status da teologia como ciência legitimada, ainda não é possível de ser avaliado, em virtude do curto período de homologação. Não

3 Dados do censo do IBGE de 2010.

4 Disponível em: http://portal.mec.gov.br/index.php?option=com docman\&view=download\&alias=48421-rces004-16-pdf\&category_slug=setembro-2016pdf\&Itemid=30192> Acesso em 10 de Maio de 2017.

Art. $2^{\circ}$ - A organização de cursos de graduação em Teologia, resguardadas as Diretrizes Curriculares Nacionais e os Pareceres desta Câmara, deverá ser elaborada com claro estabelecimento de componentes curriculares, os quais abrangerão: projeto pedagógico e matriz curricular, linhas de formação, articulação teórico-prática, processos de atualização, carga horária total, trabalhos de conclusão de curso, descrição de competências gerais e específicas, habilidades e perfil desejado para o futuro profissional, conteúdos curriculares, estágio curricular supervisionado, acompanhamento e avaliação, e atividades complementares, sem prejuízos de outros aspectos que tornem consistentes o projeto pedagógico.

5 Participaram da elaboração da minuta/2010: Augusto Nicodemos Lopes (Mackenzie); Carlos Hassel Mendes da Silva (Unievangélica-GO); Dídimo de Freitas (Associação Nacional das Escolas Presbiterianas); Pe. João Edênio R. Valle (PUC-SP); Euler Pereira Bahia (UNASP); Jocélia Moreira Moysés (Faculdade Teológica Batista- DF); José Luiz Cazarotto (Instituto Teológico de São Paulo); Klaudy Garros (Associação Brasileira de Instituições Educacionais Evangélicas); Paulo Roberto Garcia (UMESP); Ruy S. Josgrilberg (UMESP); Rudolf Eduard Von Sinner (Faculdades EST); Roberto Tambelini (Mackenzie); Lourenço Stelio Rega (Teológica Batista de São Paulo). 
constatamos quaisquer adequações feitas pelas instituições, ao menos no que concerne às grades curriculares.

O que se pode observar, dentre os objetivos da diretriz curricular comum para a teologia, é a tentativa de dar ao curso uma relevância científica; seu reconhecimento enquanto campo autônomo do conhecimento; e a emancipação do caráter endógeno-eclesial do curso. Genericamente, a diretriz segue o molde dos pareceres que estipulam encaminhamentos para outros cursos de humanidades, tais como filosofia, história etc.

Conteúdos Curriculares - Seguindo a orientação do regime jurídico de separação entre Estado e Igreja, o MEC não interferira nas grades curriculares dos cursos, sob o entendimento de que cada instituição deve organizá-las segundo suas confessionalidades, respeitando, assim, a pluralidade e liberdade religiosas no país. Com a diretriz curricular comum, foram estabelecidos quatro eixos de formação: 1) Fundamental - diz respeito às disciplinas de formação básica do curso: narrativas; línguas vernáculas do texto bíblico ou outros oficiais, hermenêutica, tradição e história; método; leis/direitos canônicos. 2) Interdisciplinar - buscar, a partir do diálogo com a filosofia, direito, história, antropologia, psicologia e sociologia, dar ênfase na formação ética e cidadã sobre, especialmente, os temas de direitos humanos; educação étnico-racial; educação indígena; educação ambiental e sustentabilidade. 3) Teórico-Prática - tem por objetivo o preparo, habilidades e competências para o exercício profissional do egresso. Conteúdos formativos, que visam à construção de um perfil que atenda aos anseios das instituições/tradições de origem. 4) Complementar - objetiva a participação do discente em atividades complementares: cursos abertos; seminários; palestras; oficinas; estágios supervisionados; grupos de pesquisa; cursos de extensão; etc. É exigido o mínimo de 200 horas para tais atividades. Outro aspecto importante a considerar na efetivação desta base curricular comum é a possibilidade do discente, caso deseje, mudar de instituição. Especificamente no caso de transferência, haverá maior aproveitamento de disciplinas, já que, atualmente, em função das grades serem bem diferentes, o aluno acaba perdendo muitos créditos e, não raras vezes, inviabiliza-se a mudança de instituição. Por fim, a diretriz propõe, a título de educação continuada, que as instituições de ensino superior criem e ofertem cursos de pós-graduação, para qualificar o ensino em nível superior e ampliar o campo de pesquisas na área da teologia.

\section{Instituições teológicas: um panorama}

Apesar do reconhecimento recente do Ministério da Educação (MEC), é notório o contributo dos seminários teológicos, não somente como cen- 
tro de formação de clérigos, mas como instituições que, transformadas em universidades, foram importantes para a construção de uma elite intelectual brasileira. Com efeito, muitos dos principais seminários teológicos ${ }^{6}$ do país, foram inaugurados bem antes que as universidades e o próprio MEC.?

No âmbito do protestantismo, praticamente todas as igrejas chamadas históricas, ao se instalarem no país, além de suas paróquias, também fundaram escolas e seminários teológicos. A partir destes, surgiram faculdades e universidades que se tornaram referências regionais e nacionais, são os casos de: Universidade Presbiteriana Mackenzie; Universidade Metodista de São Paulo; Universidade Luterana do Brasil; Centro Universitário Adventista de São Paulo, etc. Todas elas, apesar de terem o curso teológico como pioneiro, alargaram suas possibilidades de atuação na educação brasileira, passando a oferecer inúmeros cursos de nível superior e pós-graduação (lato e stricto sensu), nas diferentes áreas do saber. E, com a expansão da modalidade de ensino à distância, ampliaram ainda mais suas redes, capilarizadas em todo o território nacional por intermédio dos polos de apoio.

A respeito das instituições católicas, a inserção das mesmas no país funde-se com a própria história da colonização. A chegada dos jesuítas e das demais ordens no século XVI trazia em seu projeto missionário a implantação de escolas, seminários e, posteriormente, universidades. Pioneirismo na educação, tanto no berço europeu do medievo quanto nas colônias conquistadas na modernidade. Após a chegada da família real, em 1808, e a fundação das primeiras faculdades, a teologia esteve entre os primeiros cursos oferecidos. Figuram entre as principais instituições teológicas: Pontifícia Universidade Católica, Centro Universitário Claretiano; Centro Universitário Salesiano; Centro Universitário Assunção, e tantas outras.

Entre os evangélicos, a ascensão do grupo pentecostal, nas últimas décadas, também demandou a criação de seminários teológicos e, por conseguinte, decidiu-se investir na requisição de reconhecimento do MEC para seus cursos. À semelhança do que ocorre nas igrejas históricas, os pentecostais passaram a exigir formação teológica para aspirantes ao pastorado, como requisito obrigatório à ordenação. Já para os neopentecostais, ${ }^{8}$ a graduação em teologia

6 Seminário teológico da Corte (1867- Presbiteriano); d’O Granbery (1890 - Metodista); Seminário Teológico Batista do Norte (1902); Escola Superior de Teologia (1931-Luterana).

7 Fundado em 1930, com o nome de Ministério dos Negócios da Educação e da Saúde Púbica.

8 É um fenômeno da década de 1970, que enfatiza a cura divina, o exorcismo e a teologia da prosperidade. Uma distinção crucial é a ênfase na literatura do primeiro testamento, especificamente nos textos triunfalistas de batalhas do povo de Israel. A concepção de um deus guerreiro e nacionalista, em contraste com um Deus de amor anunciado no novo testamento, torna-se pano de fundo para a aspiração de um governo teocrático. A propagação de sua mensagem é veiculada pelas mídias de rádio e televisão. 
não aparece entre seus objetivos hodiernos - ao menos, não encontramos nenhum curso autorizado ou credenciado pelo MEC que esteja claramente vinculado às instituições neopentecostais. Seria interessante estimular outras pesquisas, que procurassem entender como o grupo neopentecostal avalia a importância - ou não - do estudo teológico para seus clérigos e fiéis.

Para além dos centros educacionais (teológicos) do cristianismo nas vertentes mencionadas acima, a representatividade de outras religiões no campo educacional teológico é, no momento, bem pequena. A título de exemplo, as religiões de matriz afro-brasileiras têm, em todo o território nacional, apenas uma faculdade teológica reconhecida pelo MEC, a saber: Faculdade de Teologia Umbandista (FTU), situada na zona sul da cidade de São Paulo. O mesmo acontece com a religião espírita, que é representada somente pela Faculdade Doutor Leocádio José Correia, situada na capital paranaense.

Segundo o sítio eletrônico do MEC, ${ }^{9}$ há 151 cursos de teologia autorizados/credenciados em atividade no país. Eles estão distribuídos em licenciaturas e bacharelados, e podem ser cursados presencialmente ou à distância. O ponto crucial que merece atenção é o fato de que faculdades não-confessionais estão interessadas em oferecer o curso de teologia. Identificou-se 17 cursos cujas instituições são laicas, algumas até bem conhecidas, tais como: Universidade Cruzeiro do Sul (UNICSUL); Universidade da Cidade de São Paulo (UNICID); Universidade do Estado de São Paulo (UNIESP). Ainda foi possível constatar 13 cursos em que não foi possível definir, com clareza, se as instituições eram laicas ou confessionais. Assim, as colocamos na categoria de indefinidas. Deste modo, estes 30 cursos (laicos e indefinidos) representam $20 \%$ do total de cursos oferecidos no país atualmente. Por tradição, os cursos de teologia tinham como objetivo a formação clerical. Contudo, com o significativo crescimento dos evangélicos no Brasil, e o reconhecimento do curso teológico, as instituições privadas com fins lucrativos visualizaram um novo e promissor nicho de mercado educacional. Por não possuir vínculos com igrejas e confessionalidades, estes cursos tendem a ter uma grade curricular mais interdisciplinar, com carga horária maior destinada às disciplinas de filosofia, sociologia e antropologia, além das pedagógicas. Assim, há uma nova perspectiva aos estudantes de teologia, a da formação teológica com aspirações docentes. A seguir, um mapeamento que pretende pôr em relevo a atual dimensão do ensino superior teológico no país. ${ }^{10}$

\footnotetext{
Disponível em:<http://portal.mec.gov.br/instituicoes-credenciadas> Acesso em 23 de Maio de 2017.

10 Mapeamento realizado com dados extraídos do site do ministério da educação. A caracterização de cada instituição educacional e sua vinculação às instituições religiosas, foram constatadas no sitio eletrônico, nas seções de "missão e valores"; "nossa história" e "mantenedora".
} 


\section{Número de cursos por religião.}

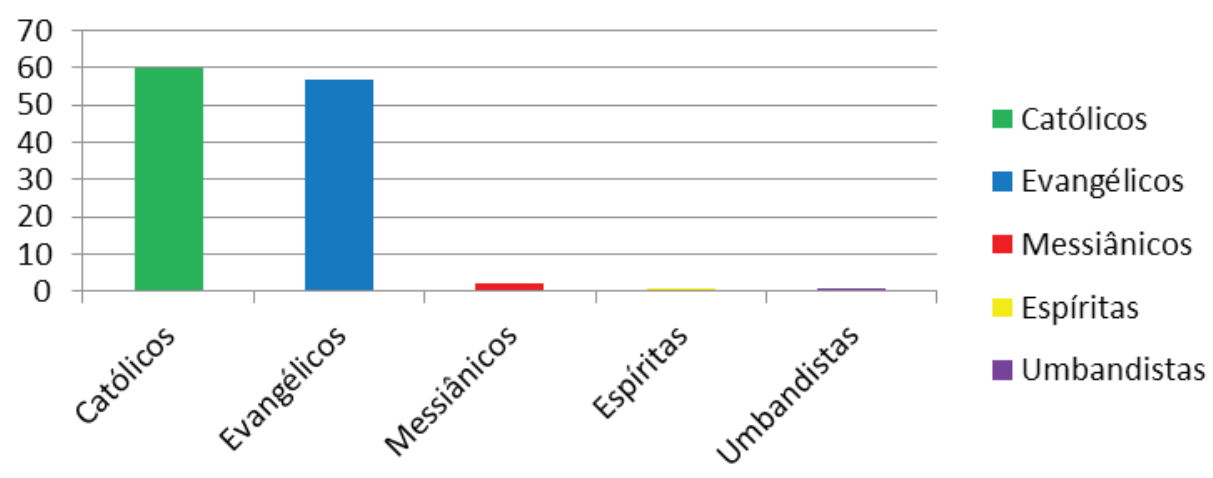

Como adiantado, mesmo sendo um país multicultural e plurirreligioso, o Brasil é majoritariamente católico (66\%), seguido dos evangélicos, em franca ascensão demográfica (22\%). Todavia, a distribuição dos cursos de teologia revela uma paridade. São sessenta cursos de vertente católica, autorizados/ reconhecidos e em andamento no país. Os evangélicos (aqui incluímos os de tradição histórica e pentecostais) possuem cinquenta e sete cursos. Semelhantemente, os espíritas $(2 \%)$ têm apenas um curso homologado, assim como os umbandistas (umbanda/candomblé - 0,3\%). A igreja messiânica, por fim, tem dois cursos. Apesar da paridade na quantidade de cursos, o destaque que se dá às instituições evangélicas, sobretudo pentecostais, é justamente pelo tempo presente no país, em relação às instituições católicas, que remontam ao período colonial, enquanto que o movimento pentecostal tem pouco mais de um século. E, ainda, é mais recente a fundação de instituições pentecostais de ensino teológico. Isso sem contar a opção de um considerado número de seminários por manter o modelo de centro formador de obreiros, sem qualquer pleito de chancela do MEC.

11 Gráfico autoral, com base no mapeamento no sítio eletrônico do MEC. 


\section{Número de cursos por confissões evangélicas}

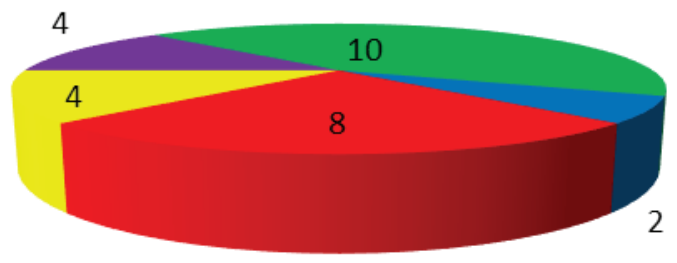

BATISTA

- PREBISTERIANA

ASSEMBLÉIA DE DEUS

ADVENTISTA

LUTERANA

Das instituições evangélicas, foi possível verificar que a Igreja Batista lidera, com 10 cursos autorizados/credenciados, seguida da Assembleia de Deus (08), ${ }^{13}$ Adventista e Luterana (04) e Presbiteriana (2). Ressalte-se que, apesar de constar com apenas dois cursos, a comunidade luterana foi a que primeiro teve o curso de teologia reconhecido pelo MEC, em 2001: as Faculdades EST, de São Leopoldo, sendo a única de viés protestante que possui mestrado e doutorado em teologia, reconhecidos pela CAPES, com conceito 6. A Igreja Metodista, também, com tradição no ensino de teologia, além de seu curso presencial na Universidade Metodista de São Paulo, ativo desde 1938, oferecido também na modalidade EAD, com avaliação de conceito máximo (5) pelo MEC. ${ }^{14}$ A Universidade Metodista também possui programa de mestrado e doutorado em Ciências da Religião. Na vertente católica, as PUC's (Pontifícia Universidade Católica) são muito conhecidas e tradicionais, contando com programas de mestrado e doutorado em teologia, além de Ciências da Religião.

No tocante as modalidades, apesar do evidente crescimento do ensino à distância, o curso de teologia tem maior oferta no presencial (85\%). São 127, enquanto o EAD tem apenas 24 cursos (15\%). Entre os tipos de graduação, o bacharelado tem 148 cursos e licenciatura apenas 3 .

12 Gráfico autoral, com base no mapeamento no sítio eletrônico do MEC.

13 Apesar de não ser a denominação com o maior número de cursos oferecidos, constatamos muitas das instituições que caracterizamos como "indefinidas", com grades curriculares que continham a disciplina de "História da Assembleia de Deus", por esta razão, a ênfase nesta instituição.

14 Disponível em:<http://portal.metodista.br/noticias/2013/fevereiro/cursos-a-distancia-da-metodista-conquistam-reconhecimento-inedito-do-mec >. Acesso em 20 de maio de 2017. 
Por fim, outro aspecto importante a observar é sobre a tendência dos corpos docentes serem constituídos, na maioria, por clérigos da própria denominação mantenedora.

\section{Tabela $1^{15}$}

COMPOSIÇÃO DE CORPO DOCENTE EM TRÊS INSTITUIÇÕES

INSTITUIÇÃO NLÉRIGO NÃO CLÉRIGO

\begin{tabular}{lll} 
PUC (SP) & $\mathbf{1 1}$ & 2 \\
MACKENZIE & $\mathbf{1 3}$ & 2 \\
METODISTA & 22 & 10 \\
\hline
\end{tabular}

Tomamos por amostragem três instituições teológicas de ampla tradição acadêmica. No caso da Pontifícia Universidade Católica de São Paulo, dez professores são padres e uma freira. A Universidade Presbiteriana Mackenzie conta com treze professores pastores da Igreja Presbiteriana do Brasil. E a Universidade Metodista de São Paulo tem, em seu corpo docente, vinte e dois clérigos da Igreja Metodista do Brasil. ${ }^{16}$ Neste último caso, apesar de haver dez professores não clérigos, $50 \%$ destes são apresentados, em seus currículos, como leigos metodistas, isto é, são membros da igreja.

\section{O status da teologia na pós-graduação}

Assim como no caso da teologia em nível de graduação, os programas de pós-graduação (stricto sensu) vêm aumentando nos últimos anos. Em 2007, na sede da Pontifícia Universidade Católica de Goiás, foi fundada a ANPTECRE (Associação Nacional de Pós-graduação e Pesquisa em Teologia e Ciências da Religião). Conforme Senra (SENRA, 2015, p.197): “naquela ocasião, eram reconhecidos pela CAPES cinco programas de Teologia e sete de Ciências da Religião". A iniciativa de criar a associação é fruto da mobilização de importantes instituições acadêmicas que se empenharam em estabelecê-la com as seguintes metas: 1) Construção colegiada da formação de uma identidade conceitual e epistemológica sob o princípio da unidade da área; 2) Construção colegiada da árvore do conhecimento e da ampliação de um canal de diálogo com o CNPq; 3) Construção colegiada de critérios avaliativos com maior diálogo com a CAPES.

\footnotetext{
15 Tabela autoral, com base nos dados dos sítios eletrônicos das três instituições de ensino citadas.

16 Quadro autoral, elaborado a partir de dados coletados a partir do sitio eletrônico de cada instituição.
} 
A associação vem promovendo congressos que estão em sua sexta edição, a ser realizada em setembro de $2017 .{ }^{17}$ Além de congressos, foram organizados grupos de trabalhos (GT's), como estratégias de qualificação continuada, visando o fortalecimento na construção da área. De fundamental importância foram os diálogos com as agências de fomento, pela busca da criação da árvore de conhecimento "Ciências da Religião e Teologia" junto ao CNPq, que já pode ser contemplada, e a autonomia da teologia enquanto área junto à CAPES. Isto ocorreu recentemente, através da publicação da portaria CAPES 174/2016, publicada no DOU de 13 de outubro de 2016, a partir do desmembramento entre as subcomissões da área de Filosofia/Teologia, que perdurava desde 1972, quando da origem de seu primeiro programa. ${ }^{18}$

A área Teologia se divide em oito subáreas: 1) ciência da religião aplicada; 2) ciências da linguagem religiosa; 3) ciências empíricas da religião; 4) epistemologias das ciências da religião; 5) história das teologias e religiões; 6) teologia fundamental-sistemática; 7) teologia prática; 8) tradições e escrituras sagradas.

\section{Tabela $2^{19}$}

\begin{tabular}{l|l|l}
\hline TOTAL DE CURSOS DA ÁREA TEOLOGIA (CAPES) \\
\hline MODALIDADE & INSTITUIÇÃO & $\begin{array}{l}\text { NOTA } \\
\text { DO } \\
\text { CURSO }\end{array}$ \\
\hline ME - DO - MP & Escola Superior de Teologia & 6 \\
\hline ME - DO & Faculdade Jesuíta & 6 \\
\hline MP & Faculdade Teológica Batista do Paraná & 3 \\
\hline ME -DO & Pontifícia Universidade Católica de Campinas & 4 \\
\hline ME & Pontifícia Universidade Católica de São Paulo & 3 \\
\hline ME- DO & Pontifícia Universidade Católica Do Paraná & 4 \\
\hline ME-DO & Pontifícia Universidade Católica de Rio de Janeiro & 5 \\
\hline ME-DO & Pontifícia Universidade Católica do RS & 4 \\
\hline ME & Universidade Católica de Pernambuco & 3 \\
\hline
\end{tabular}

São dezesseis cursos, sendo dois de mestrado profissional (MP), oito de mestrado acadêmico (ME) e seis de doutorado (DO); considerando apenas os cursos estritamente teológicos - os de nomenclatura "ciências da religião"

17 VI Congresso da Associação Nacional de Pós-graduação e Pesquisa em Teologia e Ciências da Religião: Religião, Migração e Mobilidade Urbana (13 a 15 de Setembro de 2017 - Pontifícia Universidade Católica de Goiás). https://www.anptecre.org.br/index.php?pagina=grupo_conteudo\&tela=30.

18 http://www.capes.gov.br/images/documentos/Documentos_de_area_2017/44_TEOL_docarea_2016. pdf. Último acesso em 08 de julho de 2017.

19 https://sucupira.capes.gov.br/sucupira/public/consultas/coleta/programa/quantitativos/quantitativoAreaConhecimento.jsf;jsessionid=hHzKqWQdQgGdYP+PduhNgYjA.sucupira-213?areaAvaliacao=44. 
não constam neste mapeamento. A ampliação dos programas de pós-graduação em Teologia certamente indica o fortalecimento da área. Some-se a isto o aumento do número de revistas especializadas/periódicos, bem como a participação das agências de fomento à pesquisa, seja pela concessão de bolsas de estudo (até no nível de pós-doutoramento) ou pelo financiamento de grupos de pesquisas.

Flávio Senra (2016), coordenador da área Filosofia/Teologia: subcomissão Teologia e Ciências da Religião, analisou a primeira metade do quadriênio 2013-2017. Alguns dados, mesmo que parciais, são importantes destacar:

a) o crescimento da área/subcomissão foi mais fecundo no decênio de 1983-1993, quando foram criados sete cursos, e entre 2005-2014, onze cursos. No primeiro período, foram os cursos de Teologia que mais contribuíram para o crescimento da área, enquanto que os cursos de Ciências da Religião foram os protagonistas do segundo decênio. A ampliação dos cursos de pós-graduação em Teologia se dá timidamente (média de dois cursos por década), se comparados aos de Ciências da Religião, nos últimos dez anos. Ainda assim, parece não haver assimetria entre os cursos no cômputo geral, pois representam 45\% - 55\%, respectivamente. De acordo com o Documento de Área-2016 da CAPES, temos, atualmente: 12 programas de Ciências da Religião e 11 de Teologia. ${ }^{20}$

b) quanto à produção acadêmica, a área titulou 416 discentes, sendo 108 teses de doutorado e 308 dissertações de mestrado acadêmico e trabalhos de conclusão de mestrado profissional. A produção bibliográfica e técnica (2013-2014) foram quantificadas em 7.118 produtos, destacando-se os livros (891), seguido dos periódicos (264 itens nos extratos A1-B1 e 204 nos estratos B2-B5). Em Anais, foram publicados 400 itens, enquanto a criação técnica se restringiu a apresentações de trabalhos (1093), e traduções (68). Os programas promoveram 442 eventos. Levando-se em consideração o total da produção x número de programas, tem-se 355,9 produtos por programa no período. (SENRA, 2016. p.14)

c) o Documento de Área-2016 revela assimetria de gênero quanto ao corpo docente. De um total de 307 docentes, apenas 56 (18\%) são do sexo feminino e 251 (82\%) são do sexo masculino.

d) outra assimetria encontrada é a regional. As regiões Sul e Sudeste são as que concentram a maior quantidade de programas, 5 e 10

20 http://www.capes.gov.br/images/documentos/Documentos_de_area_2017/44_ TEOL_docarea_2016.pdf. Último acesso em 08 de julho de 2017. 
respectivamente. A região Nordeste conta com 4 programas. Já as regiões Norte e Centro-Oeste, contam com um programa cada.

\section{A teologia pública como aporte epistemológico no contexto do Estado laico e plural}

Se há uma mobilização do setor acadêmico teológico em dar-lhe significância pública, procurando romper com a visão desgastada, ou mesmo discriminada que se tem dela, caberia a pergunta: de que forma poderia a Teologia fazer ecoar seus discursos frente ao contexto de uma sociedade multicultural e plurirreligiosa, estandartes das democracias modernas? Talvez, o esforço de compreender o atual regime jurídico do Estado (DALLARI, 2011, p.59), ${ }^{21}$ seja o ponto de partida. Em outros termos, trata-se de conciliar um discurso teológico relevante para um país que já rompeu com o regime de união entre Estado e Igreja. E, constitucionalmente desvinculado de qualquer religião, mesmo que pragmaticamente seja observado, em certos grupos fundamentalistas, o desejo de um governo neoteocrático. É cabível isto em um Estado que se pretende laico?

A laicidade do Estado é um pilar crucial das sociedades republicanas (cujo projeto é o bem-estar de todos os cidadãos, mormente nos regimes políticos ocidentais pós-1945), e a presença religiosa na esfera pública “[...] reascende a desconfiança pela introdução de uma lógica particularista no lugar onde só deveria prevalecer o interesse de toda a sociedade". (BURITY, 2008, p.89). É na Europa, especificamente na França, que o princípio de laicidade do Estado tem seu nascedouro (CUNHA, 2006; DOMINGOS, 2009; LACERDA, 2011). Tendo como ponto de partida a revolução política (século XVIII) e seus ideais de liberdade, igualdade e fraternidade. Campesinos, aliados à esquerda radical e à massa popular, extirparam, não sem conflitos, o regime absolutista monárquico, rompendo com os privilégios feudais, aristocratas e, sobretudo, clericais.

A natureza do período moderno dar-se-á na ruptura epistemológica balizada pela religião e seus dogmas, e, em seu lugar, assume-se a confiança na racionalidade, na ciência e na tecnologia (imbuídas no contexto da expansão do capitalismo industrial), figurando como base filosófica o movimento iluminista do século XVII-XVIII (REALE, 2007, p. 666). ${ }^{22}$ Assim, o projeto

21 Frente a inúmeras teorias de Estado, para fins deste artigo, utilizamos uma noção genérica a partir da filosofia do Direito, como: "sociedade política organizada num complexo de instituições, de autoridade soberana e que fixa as regras de convivência de seus membros em determinado território".

22 Confiança decidida, mas não ingênua, na razão, uso crítico e despreconceituoso da razão voltado para a libertação em relação aos dogmas metafísicos, aos preconceitos morais, às superstições religiosas, às relações desumanas entre os homens, às tiranias políticas: eis as características fundamentais do iluminismo. 
perpassa o abandono do modelo teocrático de governança, desmonopolizando a religião (em geral o catolicismo) deste direito, passando para um Estado autônomo jurídica e politicamente. Esta transição se dá através da separação jurídica entre Igreja e Estado, cujo primeiro país a fazer foi os EUA, com o $1^{\circ}$ aditamento à Constituição de 1791. Este processo de cisão legal entre céus e terra, sagrado e profano, se deu Ocidente afora, seguindo as particularidades de cada país.

Analisando o conceito de laicidade por autores da área educacional, clerical e jurídica, observa-se que os princípios garantidores da neutralidade do Estado, quais sejam: liberdade religiosa e igualdade formam o fio condutor por onde perpassa a ideia de laicidade.

A vivência de uma espiritualidade, ou até mesmo de nenhuma, é uma decisão particular, de foro íntimo, ao que se reserva no direito de manifestá-la privadamente, onde cada indivíduo pode, livremente, fazer suas escolhas e ser respeitado por elas. O Estado laico é aquele que reconhece o papel da religião e dá a garantia de seus respectivos cultos, mas exclui da esfera pública e jurídica toda normatividade religiosa enquanto única e suficiente detentora da verdade, tornando-se, assim, imparcial e aplicador de critérios de justiça política. Não deve ser tarefa de um Estado laico a pretensão de encaminhar os cidadãos ao encontro do bem verdadeiro, antes, tem o dever de possibilitar um espaço de convivência pacífica, conforme as convicções próprias de cada indivíduo, para que orientem sua vida nos moldes de suas próprias convicções. (FISCHMANN, 2008; MIRANDA, 2011; RHONHEIMER, 2011; MORAES, 2011).

A questão da laicidade vem sendo bastante debatida não só no país, mas em plano internacional. Passa pelas mais variadas temáticas, desde temas como aborto, pesquisa com células-tronco, casamento homoafetivo, uso de símbolos religiosos em repartições públicas, religião e educação pública, migrações, e por aí afora. No caso específico da educação pública, há controvérsia sobre a oferta da disciplina de ensino religioso. Atualmente, em todos os 27 estados da federação, o ensino religioso está sendo oferecido, e se apresenta em três modalidades: Confessional (Acre, Bahia, Rio de Janeiro e Ceará), História das Religiões (São Paulo) e Interconfessional (demais estados) (CARRIÃO; DINIZ; LIONÇO, 2010). A sustentação ou descontinuidade da oferta desta disciplina enseja muitos debates e envolve muitos atores e interesses. Os defensores do Estado laico advogam que não é tarefa da escola pública lidar com as questões de religiosidade, pois esta é questão de foro íntimo, que deve ser desenvolvida em âmbito privado. E enumera uma série de problemas que surgem a partir do oferecimento da disciplina: a) 
discriminação religiosa; b) proselitismo religioso; c) indefinição de currículo e habilitação docente, etc. Já os grupos católicos e evangélicos são a favor da disciplina e travam esta disputa em várias frentes. Em 2010, o Brasil assinou uma concordata com o Vaticano, que lhe concedia alguns benefícios, dentre os quais a garantia da oferta do ensino religioso, prioritariamente católico, na escola pública. Por sua vez, os parlamentares evangélicos vêm atuando na criação de projetos de lei que incentivam a leitura da bíblia em sala de aula, por exemplo, ou intervindo nos planos nacionais, estaduais ou municipais de educação, inclusive pedindo a supressão textual no que tange ao tema de ideologia de gênero. Estes são alguns apontamentos gerais, que procuram retratar, a partir da questão da laicidade na educação básica e pública, um dos aspectos do cenário com o qual o teólogo e a comunidade acadêmica da teologia precisam lidar e dialogar.

De que modo o conhecimento e produção teológica podem, diante deste cenário, ter relevância para a sociedade contemporânea e gozar de prestígio ao lado das outras ciências humanísticas? Existe alguma proposta que descarta a tarefa meramente eclesiocêntrica da teologia, típica dos seminários?

Há, sim! Nos anos recentes, isto pode ser observado na mobilização em torno de municiar o discurso teológico de certa significância para a sociedade civil, da qual as igrejas são apenas parte, e da sociedade científica, a partir da teologia púbica (SINNER, 2012, p. 16). ${ }^{23}$ Apesar do entendimento de que todo discurso teológico é público (TRACY, 2006, p. 19), reconhece-se o fato de que a teologia cristã destina-se a grupos pequenos, quase sempre aos fiéis, e de caráter catequético-doutrinador. A teologia pública emerge no início da década passada e, segundo o teólogo e clérigo luterano Rudolf Von Sinner, tem por objetivo: "a) tratar sobre questões da sociedade contemporânea; b) afirmar seu lugar na universidade, c) ser comunicável à comunidade científica, religiosa e política, particularmente a sociedade civil, mas também à economia" (SINNER, 2007, p. 62).

A teologia pública pretende despir-se de suas confessionalidades e, a partir disso, atingir e dialogar com uma parcela maior da sociedade, outros grupos que possuam ou não qualquer vinculação com as igrejas. Ela está interessada em acompanhar e participar na discussão de temas efervescentes que encabeçam o processo de redemocratização do país: justiça social; ética

23 A teologia pública passou a ser discutida pelo Instituto Humanitas da Unisinos, universidade jesuítica em São Leopoldo. Desde 2001, o Instituto tem publicado livros e artigos, organizado simpósios nos quais variados temas (diálogo inter-religioso, ecologia, ética, teologia na universidade, método na teologia, etc.) têm sido articulados sob o guarda-chuva conceitual de teologia pública. Também a Faculdades EST, membro fundador da Rede Global de Teologia Pública, desde 2007, vem publicando uma coleção sobre o tema. Atualmente, maio de 2017, a coleção está no sexto volume. 
social; economia; política; direitos sociais e humanos; etc. Uma teologia que dialoga com questões de sua contemporaneidade não é de todo nova, vide as teologias libertárias: negra; feminista; e da libertação. No entanto, autores tendem diferenciar a teologia pública das libertárias, e até mesmo advertem sobre o risco de confundi-la com religião civil e/ou teologia política. A teologia pública é mais dialógica que as libertárias, capaz de tratar de uma variedade de temas políticos, privando pela neutralidade, em detrimento da resistência. Esta diferenciação carece de maior aprofundamento, pois pode ser fácil atribuir o mesmo significado a ambos os conceitos (SINNER, 2007, p. 43). Vejamos como Boaventura de Souza Santos define teologia politica: "Designo por teologia política os diferentes modos de conceber a intervenção da religião, como mensagem divina, na organização social e política da sociedade" (SANTOS, 2013, p. 35). Destarte, os objetivos, tanto da teologia pública quanto política, parecem ser os mesmos.

\section{Considerações finais}

O crescimento do número de cursos em nível de graduação, especialmente pelo oferecimento por instituições não-confessionais, pode sinalizar que o campo pode ser ampliado, sem que haja apenas interesse por parte das instituições religiosas, com finalidades meramente de formação clerical. Isto pode fortalecer a ideia de que, num futuro próximo, seja fortalecida a figura do teólogo como um profissional leigo que tenha outras aspirações, sobretudo atuando enquanto pesquisador ou docente. O primeiro programa de pós-graduação em Teologia foi criado em 1972. Por 44 anos, a Teologia esteve anexada como subcomissão à área de filosofia. Agora, com sua recente emancipação, tende a trilhar seu próprio caminho, repleto de desafios, tais como o fortalecimento das regiões e a equalização das oportunidades docentes por gênero.

A academia é o locus ideal para a divulgação, produção e consolidação da Teologia enquanto ciência legitimada. Eis o grande desafio: dar-lhe o status que tivera no medievo, desta vez no contexto das res-publica, da democracia e da pluralidade religiosa. De um lado, uma universidade ancorada nos pilares do cientificismo-positivista, de outro, os cursos teológicos confessionais de modelo seminarista. Nesta encruzilhada, terá a teologia seu lugar? O teólogo tornar-se-á um profissional legitimado, para além do ofício religioso? Estarão as faculdades teológicas, sob tutela eclesiástica, dispostas a dar a seus docentes e discentes liberdade de pensar e produzir teologias que se distanciem das confessionalidades? A autonomia da Teologia enquanto área abrirá, de fato, novas oportunidades? 


\section{Referências bibliográficas}

BURITY, Joanildo. Política e cultura, Tempo Social, São Paulo, vol. 20, n. 2, p. 84-113, nov. 2008.

CARRIÃO, Vanessa; DINIZ, Débora; LIONÇO, Tatiana. Laicidade e ensino religioso no Brasil. Brasília: UNB, 2010.

CUNHA, Luiz Antonio. Ensino religioso nas escolas públicas: a propósito de um seminário internacional. Educação \& Sociedade, Campinas, vol. 27, n. 97, p. 1235-1256, set.-dez., 2006.

DALLARI, Dalmo de A. Elementos de teoria geral do Estado. 30. ed. São Paulo: Saraiva, 2011.

DOMINGOS, Marília. F. Neto. Ensino religioso e estado laico: uma lição detolerância.

Revista de Estudos de Religião, São Paulo, p. 45-70, set.-dez, 2009.

FISCHMANN, Roseli. Estado laico. São Paulo: Fundação Memorial da América Latina, 2008 .

LACERDA, Gustavo B. Laicidade (s) e República (s): as liberdades face à religião e ao estado. XXXIII Encontro ANPOCS, GT 39, Teoria Política, Caxambu, out. de 2009.

MENDONÇA, Antonio Gouvêa. Protestantes, pentecostais \& ecumênicos. São Bernardo do campo: Editora da Universidade Metodista de São Paulo, 2008.

MIRANDA, Jorge. Estado, liberdade religiosa e laicidade. In: FILHO, Ives; NOBRE, Milton. (Orgs.). O Estado laico e a liberdade religiosa. São Paulo: LT’r, 2011.

MORAES, Rafael J.S. A igreja católica e o estado laico. In FILHO, Ives; NOBRE, Milton. (org's). O Estado laico e a liberdade religiosa. São Paulo: LT’r, 2011.

PASSOS, João Décio. A construção do conhecimento legítimo: percursos e desafios para a teologia pública no Brasil. Revista de Estudos de Religião, São Paulo, vol. 25, n. 41, p. 57-76, jul.-dez., 2011.

REALE, Giovanni; ANTISERI, Dario. História da filosofia: do bumanismo a Kant. Vol. 2. São Paulo: Paulus, 1990.

RHONHEIMER, Martin. Democracia moderna, estado laico e missão espiritual da igreja. In: FILHO, Ives; NOBRE, Milton. (Orgs.). O Estado laico e a liberdade religiosa. São Paulo: LT'r, 2011.

SANTOS, Boaventura de Souza. Se Deus fosse um ativista dos direitos humanos. São Paulo: Cortez, 2013.

SENRA, Flávio. Estudo de Ciência (as) da (s) Religião (ões) e Teologia no Brasil: situação atual e perspectivas. Revista de Estudos de Religião, São Paulo, vol. 15, n. 2, p. 196-214, jul.-dez., 2015.

SINNER, Rudolf V. Confiança e convivência: reflexões éticas e ecumênicas. São Leopoldo: Sinodal, 2007.

SINNER, Rudolf V. Teologia pública: um primeiro balanço. Perspectiva Teológica, Belo Horizonte, vol. 44, n. 128, p. 11-28, jan.-abril, 2012.

TRACY, David. A imaginação analógica: a teologia cristã e a cultura do pluralismo. São Leopoldo: Unisinos, 2006.

Submetido em: 5-6-2017

Aceito em: 4-7-2017 